\title{
Contribution au dosage des caséines kappa de vache par une méthode immunoenzymatique
}

\author{
par \\ D. LEFIER* et J.-C. COLLIN**
}

\section{Rés u m é}

DOSAGE DES CASÉINES KAPPA BOVINES PAR MÉTHODE E.L.I.S.A.

La purification des caséines $\mathrm{K}$ par l'association de plusieurs techniques chromatographiques (échanges d'ions, adsorption, affinité) a permis d'obtenir un antisérum monospécifique.

Cet antisérum marqué par la phosphatase alcaline a été utilisé pour doser les caséines $\mathrm{K}$ par une technique immunoenzymatique E.L.I.S.A.

Ce dosage donne des résultats satisfaisants avec des solutions de caséines purifiées de concentrations comprises entre $10^{-3}$ et $5 \times 10^{-2} \mathrm{~g} / 1$.

Son utilisation pour le dosage des caséines $K$ dans le lait se heurte à des difficultés qui n'ont pas encore été résolues.

\section{S u $\mathrm{m} \mathbf{m}$ a $r y$}

ENZYME-LINKED IMMUNOSORBENT ASSAY OF BOVINE K CASEINS

The purification of bovine $K$ caseins through the combination of different chromatographic techniques (ion exchange, adsorption, affinity) made the preparation of a specific antiserum possible. This antiserum labelled with alkaline phosphatase was used to quantita-

* E.N.I.T.A. - Chaire de Chimie et Technologie, 21800 Quétigny.

** I.N.R.A. - Station Expérimentale Laitière, 39800 Poligny. 
tive Kappa caseins by an enzymatic-linked immunosorbent assay (E.L.I.S.A.). Results are satisfactory when this assay is performed on solutions of purified $\mathrm{K}$ caseins between $10^{-3}$ et $5 \times 10^{2} \mathrm{~g} / \mathrm{l}$. However, its application to milk is hindered difficulties which have not yet been solved.

La caséine du lait de vache est constituée de quatre protéines micellaires $\left(\alpha_{\mathrm{s} 1}, \alpha_{\mathrm{s} 2}, \beta\right.$ et $\left.\mathrm{K}\right)$ et représente $78 \%$ des matières azotées totales du lait de vache. C'est le constituant le plus important en raison de ses propriétés coagulantes qui sont la base de la formation des fromages. Actuellement la caséine entière peut être dosée par la méthode d'Aschaffenburg et Drevry (1959) par précipitation des caséines à pH 4,6 ou par "rocket immunoélectrophorèse 》 (Klostermeyer et Offt, 1978) en utilisant un sérum anti-caséine entière.

Plusieurs méthodes ont été proposées pour le dosage quantitatif des différents composants de la caséine entière, mais aucune n'est très satisfaisante. Les dosages électrophorétiques manquent de sensibilité. Par chromatographie quantitative sur hydroxyapatite (Barry et Donnelly, 1979) ou DEAE cellulose (Davies et Law, 1977), il est possible de quantifier l'ensemble des caséines $\gamma$, la caséine $K$, la caséine $\beta$ et l'ensemble des caséines $\alpha_{s}$, mais ces méthodes sont longues. Parmi les méthodes de dosage envisageables, les techniques immunoenzymatiques constituent une voie intéressante en raison de leur spécificité et de leur sensibilité. Cependant, la fiabilité de ces techniques est tributaire de la pureté des réactifs (antigène et anticorps) utilisés et c'est pourquoi il est nécessaire de disposer de fractions caséines d'une très grande pureté. Le but de cette étude étant de doser la caséine $\mathrm{K}$ de vache, le premier travail a donc été de purifier cette caséine.

\section{MATERIEL ET METHODE}

\section{La séparation des caséines $K$}

A partir d'un lait cru écrémé de grand mélange, la caséine entière est recueillie par précipitation à $\mathrm{pH} 4,6$ et fractionnée sur résine échangeuse d'ions par un gradient linéaire de $\mathrm{NaCl}$ de 0 à $250 \mathrm{mM}$ (Mercier et al., 1968). Les fractions riches en caséines $\mathrm{K}$ résultant de cette séparation sont analysées individuellement par chromatographie d'adsorption sur hydroxyapatite (Donnelly, 1977) sous l'action d'un gradient linéaire de concentration en ions phosphates de 5 à $500 \mathrm{mM}$.

Les caséines obtenues sur hydroxyapatite sont réduites par le 2 mercaptoéthanol qui est ensuite éliminé par filtration sur gel (Bio- 
Gel $\mathrm{P}_{4}$, Biorad). Les caséines issues de cette filtration subissent immédiatement une dernière chromatographie d'affinité sur gel thiolé (Brocklehurst, 1973) en utilisant du dithiodipyridine comme ligand (Mercier, 1981).

La pureté immunologique des caséines $\mathrm{K}$ ainsi isolées est testée, avant leur lyophilisation, selon la technique d'immunodiffusion double d'Ouchterlony (1948). Les anticorps de référence nous ont été aimablement fournis par le laboratoire de Biochimie et de Technologie Laitière de Jouy-en-Josas.

\section{Préparation des antisérums}

Trois lapins sont immunisés par des injections répétées de caséines émulsionnées dans de l'adjuvant complet de Freund $(0,5 \mathrm{ml}$ de solution saline $+0,5 \mathrm{ml}$ d'adjuvant). Le protocole d'immunisation comprend une première injection par voie intradermique de $1 \mathrm{mg}$ de caséine, suivie de deux injections de $3 \mathrm{mg}$ en intramusculaire à quatre et six semaines. Les prises de sang sont effectuées dix jours après la dernière injection.

La spécificité et la force des antisérums sont appréciées par la technique d'Ouchterlony (1948).

\section{Le dosage immunoenzymatique des caséines $\mathrm{K}$}

Il est réalisé selon une technique «sandwich» E.L.I.S.A. (Enzyme Linked Immuno Sorbent Assay).

Le conjugué utilisé est obtenu par couplage des anticorps avec la phosphatase alcaline (Sigma) par l'intermédiaire de la glutaraldéhyde.

Les dosages sont effectués dans des plaques de microtitration (Nunc) à 96 puits à fond plat.

Dans les cupules préalablement lavées à l'eau distillée, les dépôts de $100 \mu \mathrm{l}$ réalisés sont successivement la glutaraldéhyde à $1 \%$ dans l'eau distillée, l'immunsérum dilué dans un tampon carbonate $0,1 \mathrm{M}$ $\mathrm{pH} 9,6$, les solutions de caséines et le conjugué dilués dans un tampon PBS (phosphate mono et dipotassique $0,5 \mathrm{M}$, azide à $0,2 \%$, Tween 20 à $0,5 \%, \mathrm{NaCl} 0,15 \mathrm{M}$ ). Après chaque dépôt, la plaque est hermétiquement fermée, incubée $1 \mathrm{~h} 30$ à $37^{\circ} \mathrm{C}$, puis lavée avec le tampon PBS.

Enfin, $100 \mu l$ d'une solution de substrat de l'enzyme sont déposés. Ce substrat: le paradinitrophénylphosphate à $1 \mathrm{~g} / 1$ est dilué dans du diéthanolamine à $10 \%, \mathrm{Mg} \mathrm{Cl}_{2} 1 \mathrm{mM}$, azide à $1 \%$ ajusté à $\mathrm{pH} 9,8$ avec $\mathrm{HCl}$ concentré. La plaque est fermée et laissée $1 \mathrm{~h}$ à $37^{\circ} \mathrm{C}$ avant la mesure des absorbances à $405 \mathrm{~nm}$. 


\section{RESULTATS}

\section{Purification des caséines $K$}

L'association des techniques chromatographiques telles qu'elles ont été décrites a permis la purification des caséines $K$, ainsi que celle des autres caséines $\left(\alpha_{\mathrm{s} 1}, \alpha_{\mathrm{s} 2}\right.$ et $\left.\beta\right)$.

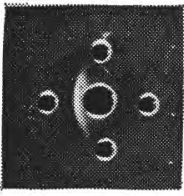

$O \beta(P) / 10$

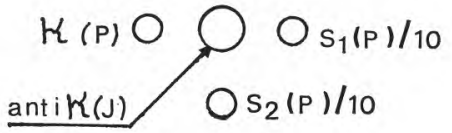

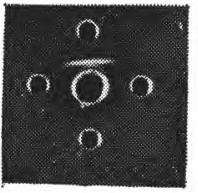

$O \beta(P) / 10$

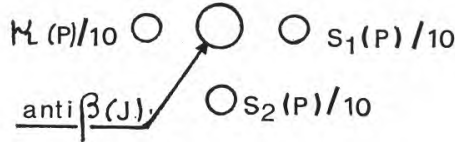

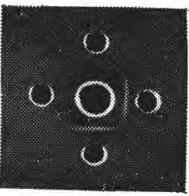

$O \beta(P) / 10$

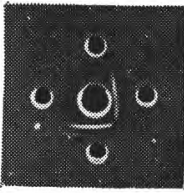

$O^{\beta(P) / 10}$

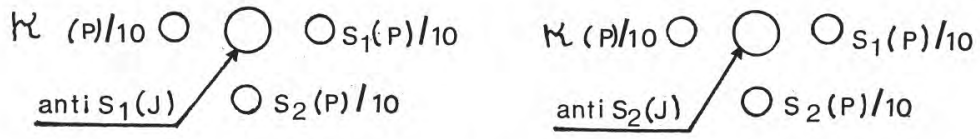

fig. 1

Contrôle de la pureté des caséines Kappa

\begin{tabular}{|c|c|c|}
\hline K & : caséines $\mathrm{K}(5 \mathrm{~g} / \mathrm{l})$. & $\mathrm{J}$ : fourni par Jouy-en-Josas \\
\hline S1 & caséines $\alpha_{S 1}(5 \mathrm{~g} / 1)$ & Poliany \\
\hline & caséines $\alpha_{\mathrm{S}_{2}}(5 \mathrm{~g} / \mathrm{l})$ & rongny. \\
\hline Anti-K & sérum d'anticaséines $\mathrm{K}$. & s1 $\mathrm{J} / \mathrm{i}: \mathrm{i}:$ degré de dilution. \\
\hline Anti- $\beta$ & sérum d'anticaséines $\beta$. & \\
\hline $\begin{array}{l}\text { Ant1-s1 } \\
\text { Anti-s2 }\end{array}$ & $\begin{array}{l}\text { serum d'anticaséines } \alpha_{\mathrm{S} 1} \text {. } \\
\text { sérum d'anticaséines } \alpha_{\mathrm{S} 2}\end{array}$ & \\
\hline
\end{tabular}

Control of the purety of K-caseins 


\section{Pureté immunologique de la préparation de caséines $\mathbf{K}$}

L'étude en immunodiffusion de notre préparation de caséines $\mathrm{K}$ vis-à-vis des antisérums de référence fournis par Jouy-en-Josas montre (fig. 1) :

- l'absence d'arc de précipitation avec les antisérums anti- $\beta$, anti- $\alpha_{\mathrm{s} 1}$ et anti- $\alpha_{\mathrm{s} 2}$;

- la présence d'un seul arc de précipitation avec l'anti-K.

En conséquence, la pureté immunologique de notre préparation antigénique paraît satisfaisante.

\section{Spécificité de l'antisérum}

L'antisérum que nous avons obtenu réagit (fig. 2) avec notre préparation de caséines $\mathrm{K}$ en donnant un seul arc de précipitation et ne réagit pas avec les autres caséines. La spécificité paraît donc satisfaisante.
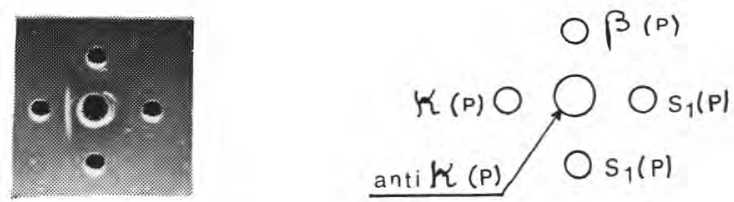

fig. 2

Contrôle de la spécificité de l'immunsérum. Description des anticorps et des antigènes : idem figure 1.

Control of the specificity of the immune serum.

\section{Dosage des caséines $K$ purifiées}

La courbe d'étalonnage obtenue à partir de solutions de caséines $\mathrm{K}$ purifiées est représentée sur la figure 3. La partie linéaire de cette courbe définit le domaine de concentration utilisable pour le dosage : entre $10^{-3}$ et $5 \cdot 10^{-2} \mathrm{~g} / \mathrm{l}$. Cependant, ce dosage nécessite un réétalonnage pour chaque plaque.

\section{Essai de dosage des caséines $K$ du lait}

Le dosage des caséines $\mathrm{K}$ dans le lait nécessite la solubilisation des micelles de caséines. Les différents traitements de solubilisation des micelles: adjonction d'urée, d'EDTA ou de citrate trisodique, ne conduisent pas à des résultats satisfaisants (fig. 4). Cependant, l'urée à une concentration finale $2 \mathrm{M}$ semble avoir un effet favorable sur la solubilisation des micelles de caséines puisque les absorbances mesurées dans ce cas sont plus fortes.

L'écrémage du lait n'améliore pas les résultats. 


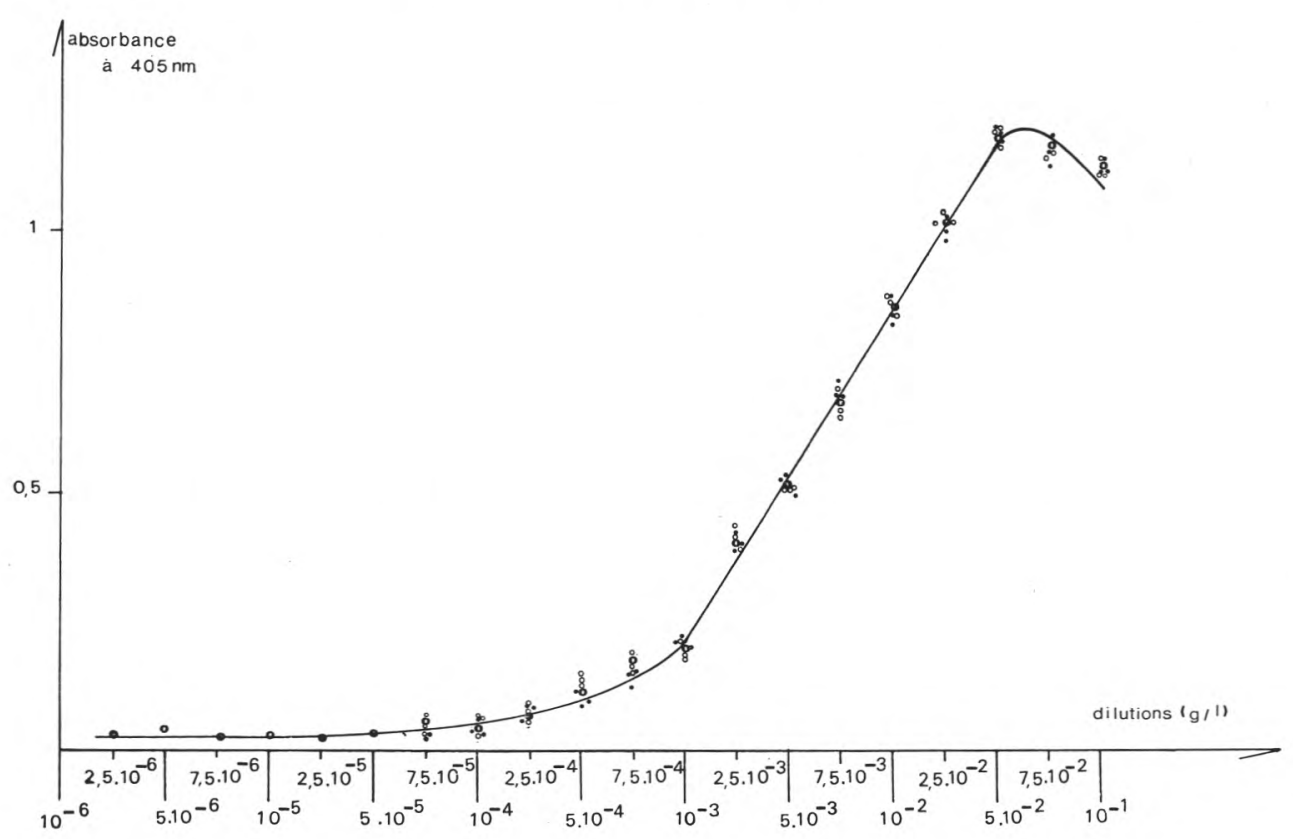

fig. 3

Dosage des caséines $\mathrm{K}$ par la méthode E.L.I.S.A.

. Donnée d'une plaque.

- Donnée d'une seconde plaque.

O Moyenne des six données.

Determination of K-casein by E.L.I.S.A. method

\section{DISCUSSION ET CONCLUSION}

La purification des caséines $\mathrm{K}$ a permis la synthèse d'un antisérum monospécifique. En conséquence, le dosage, par la méthode E.L.I.S.A., des caséines $\mathrm{K}$ purifiées a été possible. Par contre, le dosage des caséines $\mathrm{K}$ dans le lait n'a pas donné de résultats satisfaisants.

Il est à noter que les caséines $\mathrm{K}$ présentent une forte immunogénicité et l'antisérum produit s'avère monospécifique sans aucun traitement. 


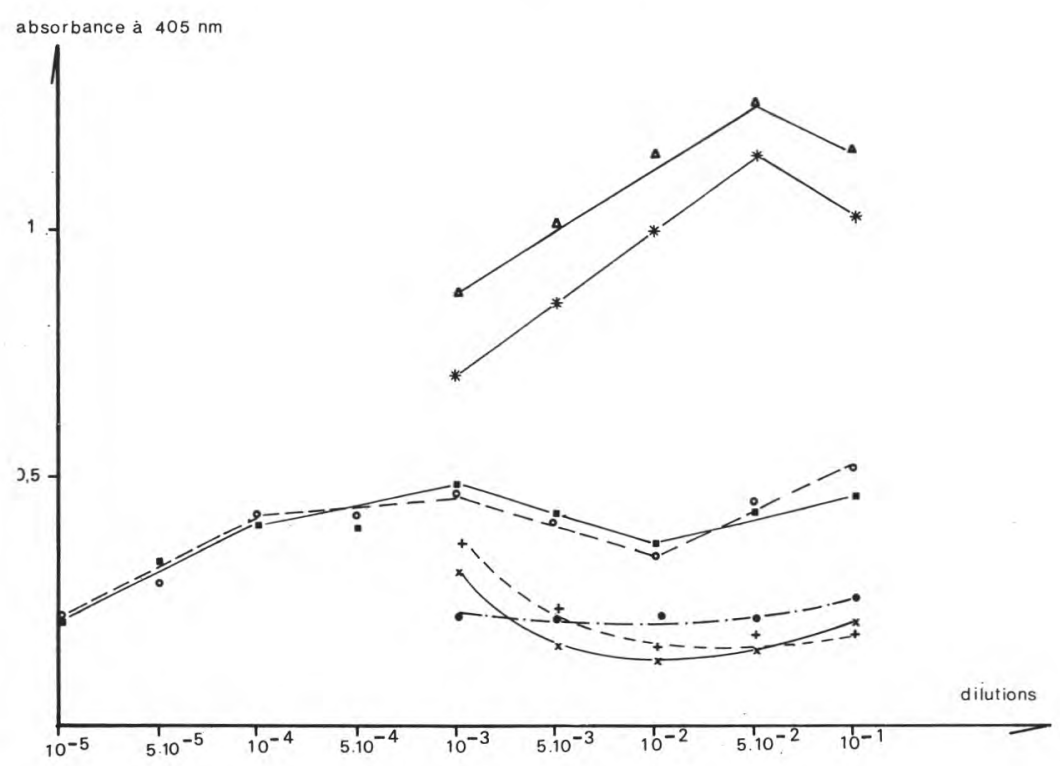

fig. 4

Essai de solubilisation des micelles de caséines et de dosage des caséines $K$ dans le lait

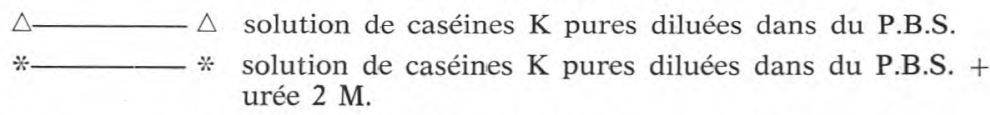

O - - - o lait cru dilué dans du P.B.S. + urée 2 M.

- lait écrémé dilué dans du P.B.S. + urée $2 \mathrm{M}$.

-._._._. - lait écrémé dilué dans du P.B.S. + citrate 0,1 M.

$\times \longrightarrow$ lait écrémé dilué dans du P.B.S. + EDTA 0,1 M.

$+-\ldots+$ lait cru dilué dans du P.B.S.

Solubilization of casein micelles and determination of $K$-casein in milk

L'application de la technique E.L.I.S.A. au dosage des caséines $\mathrm{K}$ dans le lait exige la dissociation des micelles de caséines afin de démasquer les déterminants antigéniques des caséines $K$. Cette action ne doit pas nuire à l'établissement du complexe antigèneanticorps dont les liaisons sont de même nature que celles qui maintiennent les caséines sous une forme micellaire. Les faibles résultats obtenus pourraient notamment être attribués à une dissociation insuffisante des micelles. Ces essais sur le lait doivent être poursuivis. 


\section{Bibliographie}

AschafFenburg (R.) and DRevry (J.) (1959). - New procedure for the routine determination of the various non casein proteins of milk. $15^{\circ}$ Cong. Int. Lait, Londres, 3, 1631-1637.

BarRy (J. G.) and Donnelly (W. J.) (1979). - A method for the quantitative analysis of bovine casein. Biochem. Soc. Trans., 7, 529-531.

Brocklehurst (K.), Carlsson (J.), Kierstan-MaeK (P. J.), M. CRooK (E.) (1977). Covalent chromatography by thiol disulfide interchange. Biochem. Journ., vol. 133, 531-537.

DaviES (D. T.) and LAW (J.R.) (1977). - An improved method for the quantitative fractionation of casein mixtures using ion - exchange chromatography. J. Dairy Res., 44, 213-221.

DoNNELLY (W. J.) (1977). - Chromatography of milk proteins on hydroxyapatite. J. Dairy Res., 44, 621-625.

Klostermeyer (H.) and OfFt (S.) (1978). - Immunological analysis of the casein proportions in heated food and feedstuffs. Z. Lebensm. Unters. Forsch., 167, 158-161.

LEFIER (D.) (1981). - La purification des principaux constituants protéiques de la caséine entière et contribution au dosage des caséines Kappa par la méthode E.L.I.S.A Mémoire de fin d'études E.N.I.T.A., Dijon.

Mercier (J. C.), Maubois (J. L.), Poznanski (S.), Ribadeau-Dumas (B.) (1968). Fractionnement préparatif des caséines de vaches et de brebis par chromatographie sur D.E.A.E. cellulose en milieu urée et 2-mercaptoéthanol. Bull. Soc. Chim. Biol., 50, $n^{\circ}$ 3, 521-530.

MercieR (J. C.) (1981). - Communication personnelle.

OUCHTERLONY (Ö) (1948). - In vitro method for testing the toxin producing capacity of diphteria bacteria. Acta Pathol. Microbiol. Scandinavia, 25, 186-191. 